\title{
Impact of psychiatric profile and personality trait on directly observed tuberculosis treatment outcome
}

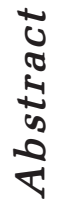

Sudhir Chaudhri, Anup Bansal, Arpita Singh 1 , Arun Sampath, Ajay Kumar Verma ${ }^{2}$, Adarsh Tripathi', Mayank Mishra, Sushil Kumar Verma

Departments of Tuberculosis and Respiratory Diseases, ${ }^{1}$ Pharmacology, Ganesh Shankar Vidyarthi Memorial Medical College, Kanpur, ${ }^{2}$ Departments of Pulmonary Medicine, King George's Medical University, Lucknow, Uttar Pradesh, India

Address for the Correspondence: Dr. Ajay Kumar Verma, Department of Pulmonary Medicine, King George's Medical University, Lucknow - 226003 , Uttar Pradesh, India. E-mail: drajay21@gmail.com

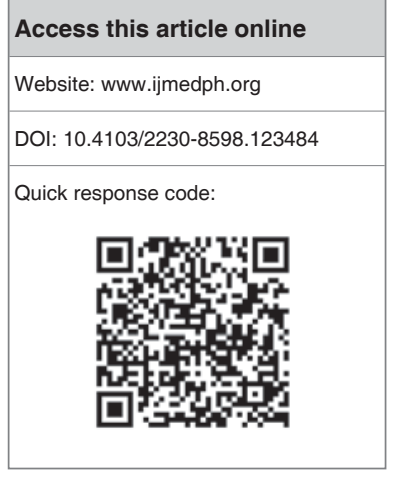

Background: Psychiatric morbidity in tuberculosis (TB) patients is well-known and its impact on treatment compliance needs to be evaluated. Objectives: To study psychiatric profile, personality trait of TB patients registered on directly observed treatment-short course (DOTS) and to evaluate their impact on treatment completion and default. Materials and Methods: Psychiatric morbidity and personality traits were assessed by Cornell Medical Index and 16PF personality questionnaire, respectively. Patients with psychiatric comorbidity were randomized into two groups. Group A: DOTS with psychiatric intervention and Group B: DOTS alone. They were followedup till treatment completion. Results: Out of 214 patients registered, $176(82.2 \%)$ had psychiatric comorbidity. $150(85.2 \%)$ had anxiety neurosis, and $26(14.8 \%)$ had depression. On personality assessment, $54.1 \%$ were neurotic, $26 \%$ introverts, $15.8 \%$ extroverts, and $4.1 \%$ had other traits. Forty-one $(23.3 \%)$ patients defaulted. Default rate was low (13.6 vs $33 \%, P=0.002$ ) and patient retrieval was good (67 vs $24 \%, P=0.01$ ) in group $A$. Patients with neurotic trait defaulted more $(P=0.006)$. On multivariate analysis, smoking (odds ratio $(\mathrm{OR})=3.76,95 \%$ confidence interval (CI): 1.7-8.28); alcoholism (OR $=15.4, \mathrm{Cl}$ : 6.67-35.72); and neurotic personality $(\mathrm{OR}=3.54, \mathrm{Cl}: 1.61-7.79)$ were strongly associated with default whereas age, sex, social class, literacy, and psychiatric morbidity type were not. Conclusion: Pretreatment psychological assessment and intervention reduces default rate.

Key words: Anxiety neurosis, default, neurotic, treatment compliance

\section{INTRODUCTION}

Noncompliance to tuberculosis (TB) treatment is a major problem that leads to treatment failure, relapses, and emergence of drug resistance. ${ }^{[1]}$ However, over the years one of the main efforts in reducing TB prevalence has been directed towards direct observed therapy-short course (DOTS) to enhance compliance to TB medication. Even though DOTS improved treatment compliance, many patients default due to various sociodemographic and treatment related risk factors. ${ }^{[2]}$ Various studies have reported that there is high incidence (50-80\%) of personality and psychological factors involved in TB patients which affect the treatment compliance and influence treatment outcome. ${ }^{[3,4]}$ Psychological interventions with either antipsychiatric drugs or by behavioral counseling methods have shown benefit in TB patients with psychiatric morbidity ${ }^{[-7]}$ The present study was conducted to evaluate the possible influence of psychiatric morbidity and personality traits on treatment completion and drug default in TB patients on DOTS.

\section{MATERIALS AND METHODS}

\section{Study subjects}

The study was a prospective randomized controlled study conducted in the Department of Tuberculosis and Respiratory Diseases, Ganesh Shankar Vidyarthi Memorial Medical College (GSVMMC), Kanpur, India from January 2008-January 2009. The inclusion criteria for recruitment of subjects into this study were: 1) Patients with new pulmonary and extrapulmonary TB diagnosed at the designated 
microscopy center (DMC) and enrolled in DOTS center, GSVMMC, Kanpur; 2) informed consent at baseline; and 3) willingness to attend regular follow-up visits. The exclusion criteria were: Age $<18$ years, retreatment TB (DOTS category II) cases, known psychiatric illness, positive human immunodeficiency virus (HIV) serology, multidrug resistant (MDR) TB suspects, pregnant, and lactating females. After enrolment, a thorough clinical history was taken and then subjected to detailed clinical examination. The study was approved by the institutional ethics committee, GSVMMC, Kanpur, India.

All the patients received a standardized 6 months intermittent (thrice weekly) anti-TB treatment (DOTS) as per the Revised National Tuberculosis Control Program (RNTCP) protocol. All the drugs were given under supervision by a DOTS provider during initial 2 months intensive phase and partly supervised during continuation phase. Patients were regularly followed-up during each visit and sputum microscopy was done as per RNTCP guidelines. ${ }^{[8]}$ Those patients who failed treatment were put on category II DOTS retreatment regime. In the event of a default, the patients were dealt with standard default retrieval actions specified in the RNTCP guidelines.

\section{Treatment outcomes}

Patients were defined 'cure' for those who completed the treatment and remained sputum negative at the end of treatment. The term 'treatment completed' was applied to patients who completed a full course of treatment, had negative sputum at 2-6 months after initiation, but without sputum result at completion. Patients with a positive sputum smear at 5 months after initiating the treatment or initially smear negative patients became sputum positive during any time of treatment were classified as 'treatment failure'. Those patients who stopped taking treatment for 2 months or more during the course of treatment were termed 'default'. Patients who died due to any cause during the treatment course were termed 'died" ${ }^{[8]}$ 'Treatment success' included both cured and treatment completed patients.

\section{Psychological assessment}

Psychiatric morbidity was assessed by Hindi (local vernacular language) version of Cornell Medical Index (CMI) developed at Post Graduate Institute of Medical Education and Research, Chandigarh, India. ${ }^{[9]} \mathrm{CMI}$ is a questionnaire which comprises of sections A-R (total 195 questions) and of which section M-R (questions 49-99) diagnose broader group such as depression and anxiety. The personality type was assessed by the 16-PF personality questionnaire (Hindi Edition, Cattell adapted by S. D. Kapoor) which comprises of 16 personality factors (factor A-Q4). ${ }^{[10-12]}$ Based on this assessment, personality traits were classified into: Introvert, extrovert, neurotic, openness, mindedness, self-controlled, and unrestrained. Patient's awareness of the nature of disease and their degree of self-motivation were assessed as described elsewhere. ${ }^{[13]}$ The personality assessment was done only at the time of enrolment, whereas psychiatric assessment and intervention was done at the enrolment and fortnightly during intensive phase and monthly during continuation phase of DOTS therapy. After initial assessment, patients with psychiatric morbidity were enrolled and randomized into two groups: Group A (DOTS therapy along with psychiatric intervention) and group B (only DOTS therapy). All the patients were regularly followed-up regularly till treatment completion.

\section{Psychiatric intervention}

Those patients who had psychiatric illness were given behavioral counseling and antipsychiatric treatment were given appropriately. A total of eight sessions were planned coinciding with the same day of drug collection visits and were given fortnightly during the first 2 months of the intensive phase and at monthly intervals during the continuation phase of treatment. Individual psychotherapy sessions were taken on the same days as the patients were due to collect their drugs. Initial sessions were of $1 \mathrm{~h}$ duration and focused primarily on rapport formation. Subsequent sessions were of approximately 30-45 min in which motivational interviewing was done on the lines of the Motivational Enhancement Therapy (MET) of Prochaska and DiClemente. ${ }^{[13]}$ Decision to start antipsychiatric drugs (for anxiety/depression) was taken by the expert psychiatrist. Treatment duration for antipsychiatric drugs was decided based on the follow-up psychiatric assessment.

\section{Statistical methods}

Parametric data is expressed as mean \pm standard deviation SD) and nonparametric data as median (interquartile range). We used independent sample $t$-test to identify significant differences in continuous variables between the two groups, and the chi-square test for categorical variables. We performed univariate logistic regression analysis with default as response variable and mean age, sex, marital status, education status, occupation status, smoking, alcohol addiction, mean duration of illness before starting DOTS, type of psychiatric morbidity, and personality trait as predicted variables. Statistical significance was assessed at a two-tailed $P$-value $<0.05$. All the statistical analysis was performed using Statistical Package for Social Sciences (SPSS) 13.0 (Chicago, USA).

\section{RESULTS}

A total of 296 patients got enrolled in the DOTS center and out of which, 82 patients were excluded due to the following reasons: 73 retreatment cases; two patients with established psychiatric illness; four MDR TB suspects, and three pregnant ladies. Out of 214 patients included in the study, $176(82.2 \%)$ patients had psychiatric morbidity and they were randomized in two groups: Group A $(n=88)$ and group B $(n=88)$. Fifty-six percent of patients were males and the mean age of study subjects was $27.53 \pm 0.9$ years. About $62 \%$ of patients were from rural area and $73.5 \%$ belonged to low socioeconomic status. Thirty-nine percent of patients were illiterates. The mean duration of illness before inclusion in the study was $5.1 \pm 0.9$ months. The radiological extent of disease was minimal in $64.2 \%$ and moderate to far advance in $35.8 \%$ cases. Sixty-six percent of patients were tobacco chewers, $52 \%$ 
were smokers, and $24 \%$ were alcoholics. The demographic data of study subjects is given in [Table 1]. Overall, there was no statistically significant difference in the demographics between the two groups.

Majority $(85.2 \%)$ of patients had anxious neurosis and the rest $(14.8 \%)$ had depression. [Table 2] There was no statistically significant difference between the groups in terms of psychiatric morbidity. On personality assessment, results showed predominance of personality factors C, E, I, and O and out of which majority of patients were apprehensive (84\%) followed by those affected by feelings (84\%), submissive(76\%), and sensitive (76\%). Based on these primary personality factors, $53.4 \%$ were found to be neurotic, $26.2 \%$ introverts, $18.2 \%$ extroverts, and $2.2 \%$ patients had other personality traits. Based on these traits the study patients could be characterized as emotionally labile, tender mind, and overprotected nature.

\begin{tabular}{|c|c|c|c|}
\hline Characteristics & Group A & Group B & $P$-value \\
\hline Number of patients & 88 & 88 & \\
\hline Males $(n, \%)^{*}$ & 51,58 & 47,53 & 0.54 \\
\hline Age $($ mean $\pm S E) \#$ & $26.97 \pm 0.9$ & $28.09 \pm 0.91$ & 0.38 \\
\hline Rural area of residence $(n, \%)^{*}$ & $61,69.3$ & $63,71.6$ & 0.88 \\
\hline $\begin{array}{l}\text { Low socioeconomic } \\
\text { status }(n, \%)^{*}\end{array}$ & 66,75 & 63,72 & 0.60 \\
\hline Literacy rate $(\%)$ & 61.4 & 60.2 & 0.64 \\
\hline Employed (skilled worker) & 40 & 41 & 0.98 \\
\hline Employed (unskilled worker) & 34 & 33 & \\
\hline Unemployed & 14 & 14 & \\
\hline Marital status: Married $(n, \%)$ & $47,53 \%$ & 51,58 & 0.54 \\
\hline Body weight (mean $\pm S E)^{\#}$ & $47.82 \pm 0.87$ & $49.26 \pm 0.88$ & 0.24 \\
\hline $\begin{array}{l}\text { Duration of illness (mean } \pm S E)^{\#} \\
\text { (months) }\end{array}$ & $5.3 \pm 1.2$ & $4.9 \pm 0.8$ & 0.46 \\
\hline Smoking habit $(n, \%)^{*}$ & 45,51 & 47,53 & 0.76 \\
\hline Tobacco chewer $(n, \%)^{*}$ & $57,64.7$ & 60,68 & 0.63 \\
\hline Alcoholic $(n, \%)^{*}$ & 17,19 & 25,28 & 0.16 \\
\hline \multicolumn{4}{|l|}{ Radiological extent of disease ${ }^{\$ *}$} \\
\hline Minimal disease & $54,61 \%$ & $59,67 \%$ & 0.43 \\
\hline $\begin{array}{l}\text { Moderate to far advanced } \\
\text { disease }\end{array}$ & $34,39 \%$ & $29,33 \%$ & 0.43 \\
\hline Cavitations in X-ray & $24,23 \%$ & $22,25 \%$ & 0.73 \\
\hline
\end{tabular}

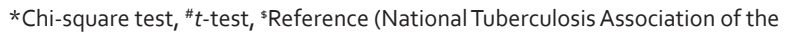
USA. Diagnostic Standards and Classification of Tuberculosis. New York: National Tuberculosis Association, 1961), SE = Standard error

\begin{tabular}{|c|c|c|c|}
\hline & \multicolumn{2}{|c|}{ Psychiatric morbidity } & \multirow[t]{2}{*}{$P$-value } \\
\hline & Anxiety & Depression & \\
\hline \multicolumn{4}{|l|}{ Group A (88) } \\
\hline Count & 72 & 16 & 0.202 \\
\hline Proportion & $81.8 \%$ & $18.2 \%$ & \\
\hline \multicolumn{4}{|l|}{ Group B (88) } \\
\hline Count & 78 & 10 & \\
\hline Proportion & $88.6 \%$ & $11.4 \%$ & \\
\hline
\end{tabular}

Twelve patients $(12 / 88,13.6 \%)$ in group A defaulted, of whom eight $(8 / 12,66.7 \%)$ could be retrieved back. In group B, 29 (29/88, 33.4\%) defaulted, of whom only seven $(7 / 29,24.1 \%)$ patients could be retrieved back. Majority $(75.6 \%)$ of the default occurred in intensive phase and out of them mostly in $<1$ month period. Patients in group A were significantly less defaulted $(P=0.002)$ and were able to retrieve them back to treatment more than the group $\mathrm{B}(P=0.01)$ [Table 3]. Out of eight patients in group A who were retrieved, six had treatment success and two failed treatment. Out of seven retrieved patients in group B, five had treatment success and two failed treatment. Neurotic personality patients defaulted more as compared to other personality traits $(31 / 94$ vs $10 / 82, P=0.008)$ and they were retrieved less as compared to others $(9 / 31$ vs $6 / 10$, $P=0.006$ ). But neurotic patients in group A defaulted less and were retrieved more as compared to those in group $\mathrm{B}$.

A total of 130 (73.9\%) patients had treatment success (76 in group $A$ and 54 in group B) and there was significant difference between the two groups $(P=0.0003)$ [Table 4]. Treatment failure occurred in $19(10.8 \%)$ patients (seven in group A and 12 in group B) and the difference between the groups was insignificant. One patient in group A died due to massive hemoptysis.

As group B was our nonintervention group so we did not see much benefit in group B, but still because of DOTS treatment we have seen good treatment success rate and little default retrieval rate.

\section{Logistic regression analysis}

Of the variables tested, smoking (OR: 3.76, 95\% CI: 1.71-8.28, $P=0.001$ ); alcohol addiction (OR: 15.42, 95\% CI: 6.67-35.72,

\begin{tabular}{|c|c|c|c|}
\hline & Group A & Group B & $P$-value \\
\hline Defaulted & $12 / 88(13.6 \%)$ & $29 / 88(33.4 \%)$ & 0.002 \\
\hline Default retrieval & $8 / 12(66.7 \%)$ & $7 / 29(24.1 \%)$ & 0.01 \\
\hline
\end{tabular}

\begin{tabular}{lccc}
\multicolumn{4}{c}{ Table 4: Treatment outcome among study subjects } \\
\hline Treatment outcome & Group A (88) & Group B(88) & P-value \\
\hline Failure & & & \\
Count & 6 & 10 & 0.001 \\
Proportion & $37.5 \%$ & $62.5 \%$ & \\
Success & & & \\
$\quad$ Count & 69 & 49 & \\
$\quad$ Proportion & $58.5 \%$ & $41.5 \%$ & \\
Default but retrieved & & 7 \\
$\quad$ Count & 8 & $46.7 \%$ \\
$\quad$ Proportion & $53.3 \%$ & & \\
Default but lost & & 22 \\
Count & 4 & $84.6 \%$ \\
Proportion & $15.4 \%$ & 0 \\
Died & & 0 \\
Count & 1 & \\
Proportion & $100 \%$ &
\end{tabular}


$P<0.001$ ); and neurotic personality trait (OR: 3.54, 95\% CI: $1.61-7.79, P=0.002)$ were related to the default in the univariate logistic regression analysis [Table 5]. The other variables like age, sex, education, marital status, and social class did not influence default rate. Similarly, there was no significant difference in default rate among different types of psychiatric morbidity.

\section{DISCUSSION}

Nonadherence to treatment is common in patients with chronic illness. ${ }^{[14-17]}$ Multiple factors are responsible for nonadherence and

\begin{tabular}{|c|c|c|c|c|}
\hline Factors & Defaulters & $\begin{array}{c}\text { Non- } \\
\text { defaulters }\end{array}$ & OR (95\% Cl) & $P$-value \\
\hline Age (Mean $\pm S D)$ & $28.29 \pm 0.8$ & $27.43 \pm 0.9$ & $\begin{array}{c}0.93 \\
(0.46-1.12)\end{array}$ & 0.86 \\
\hline \multicolumn{5}{|l|}{ Gender } \\
\hline Male & 25 & 73 & $\begin{array}{c}0.85 \\
(0.36-2.04)\end{array}$ & 0.72 \\
\hline Female & 16 & 62 & & \\
\hline \multicolumn{5}{|l|}{ Marital status } \\
\hline Married & 24 & 74 & $\begin{array}{c}1.16 \\
(0.57-2.36)\end{array}$ & 0.67 \\
\hline Unmarried & 17 & 61 & & \\
\hline \multicolumn{5}{|l|}{ Education status } \\
\hline Literate & 28 & 76 & $\begin{array}{c}1.67 \\
(0.79-3.51)\end{array}$ & 0.17 \\
\hline Illiterate & 13 & 59 & & \\
\hline \multicolumn{5}{|l|}{ Occupation } \\
\hline Skilled worker & 21 & 61 & $\begin{array}{c}1.27 \\
(0.63-2.56)\end{array}$ & 0.49 \\
\hline $\begin{array}{l}\text { Unskilled } \\
\text { workers }\end{array}$ & 16 & 49 & & \\
\hline Employed & 4 & 25 & & \\
\hline \multicolumn{5}{|l|}{ Social class } \\
\hline Lower class & 31 & 98 & $\begin{array}{c}1.17 \\
(0.52-2.62)\end{array}$ & 0.69 \\
\hline $\begin{array}{l}\text { Middle and } \\
\text { upper class }\end{array}$ & 10 & 37 & & \\
\hline \multicolumn{5}{|l|}{ Smoking addiction } \\
\hline Smokers & 31 & 61 & $\begin{array}{c}3.76 \\
(1.7-828)\end{array}$ & 0.001 \\
\hline Nonsmokers & 10 & 74 & & \\
\hline \multicolumn{5}{|l|}{ Alcoholic addiction } \\
\hline Alcoholic & 27 & 15 & $\begin{array}{c}15.42 \\
(6.67-35.72)\end{array}$ & $<0.001$ \\
\hline Nonalcoholic & 14 & 120 & & \\
\hline \multicolumn{5}{|c|}{ Psychiatric morbidity } \\
\hline Anxiety & 37 & 113 & $\begin{array}{c}1.80 \\
(0.58-5.50)\end{array}$ & 0.043 \\
\hline Depression & 4 & 22 & & \\
\hline \multicolumn{5}{|l|}{ Personality trait } \\
\hline $\begin{array}{l}\text { Neurotic } \\
\text { personality trait }\end{array}$ & 31 & 63 & $\begin{array}{c}3.54 \\
(1.61-7.79)\end{array}$ & 0.002 \\
\hline $\begin{array}{l}\text { Nonneurotic } \\
\text { personality trait }\end{array}$ & 10 & 72 & & \\
\hline
\end{tabular}

of which psychiatric morbidity and personality of patient may be an important factor responsible for drug default and usually overlooked. ${ }^{[18-22]}$ In the present study, a total of $176(82.2 \%)$ patients had psychiatric morbidity. Eighty-five percent of patients had anxiety neurosis, and the rest had depression. Forty-one (23.3\%) patients interrupted from DOTS therapy and this was higher as compared to overall RNTCP reported default rate from the same region. This might be due the fact that all the patients included in the study had psychiatric morbidity. On comparison, the intervention group (A) had fewer defaults as compared to the other group (B). Similarly, $67 \%$ of defaulted patients in group (A) were retrieved as compared to only $24 \%$ in group B. The overall treatment success was significantly higher in group A $(86.4 \%)$ as compared to $61.4 \%$ in group B and this difference might be due to the higher number of patients completing full course of DOTS in group A. The treatment failure rate between the groups was not significant. Hence, we noticed that psychiatric intervention reduced the default and increased the default retrieval and thereby increased the treatment success. Seetha et al. ${ }^{[23]}$ concluded that attempts to improve motivation by regular home visits educating family members resulted in higher treatment completion rate. Uplekar and Rangan ${ }^{[24]}$ too noted that educating and motivating patient and their peers through group meetings at the time of drug collection favorably influences treatment adherence. We also noted that majority of default $(75 \%)$ occurred in intensive phase. Treatment interruption in the initial period of treatment could lead to acquired drug resistance and hence reducing default will improve treatment success and reduce emergence of drug resistance. ${ }^{[25,26]}$ Hasker et al. ${ }^{[25]}$ noticed that default was a serious problem in the TB program and occurred mostly during the intensive phase. They also observed that one-third of defaulters did not really defaulted, but continued treatment under non-DOTS conditions which increased the risk of irregular treatment and associated development of drug resistance.

In all, $53.4 \%$ patients were neurotic, $26.2 \%$ introverts, $18.2 \%$ extroverts, and $2.2 \%$ had other personality traits. Majority of patients were emotionally labile, affected by feelings, submissiveness in nature, tender minded, and overprotective by nature (i.e. very much sensitive and apprehensive). Similar observations were made by others. ${ }^{[27,28]}$ In the present study, defaulters were high in neurotic personality traits, less in introverts, and nil in extroverts. Various authors had similarly reported that defaulters were the ones who involve less in the environment. ${ }^{[11,29]}$ Neurotic personality patients defaulted more and were less retrieved back as compared to other personality traits irrespective of the groups. On contrary, neurotic patients who had psychotherapy (group A) defaulted less and was retrieved more as compared to neurotic patients in group B. Hence, behavioral counseling was effective in influencing favorable treatment outcome. Behavior modification by effective psychotherapy had played important role in improving treatment compliance and reduces treatment failure and drug resistance. Repeated motivation and counseling increased treatment completion rate and single session might not suffice. ${ }^{[30]}$ 
During the pretreatment assessment, we observed that majority of the patients had a very poor conceptual understanding of the disease. Very few patients could tell that TB is a contagious disease. Majority of patients thought that TB is incurable. The themes for psychotherapy sessions were structured according to the conceptual understanding of an individual patient obtained from pretreatment psychological assessment. For most of our patients, TB meant nothing but their physical symptoms. The implication of this ignorance or their concept that the symptoms are the real disease may also be responsible for premature interruption of their treatment. Many researchers have observed that most patient default as soon as they become asymptomatic ${ }^{[31]}$ perhaps considering themselves cured of the disease. Therefore, better understanding of the disease process is a must with emphasis on completion of the full regimen to achieve cure. This aspect was taken care of under specific counseling during psychotherapy sessions.

Out of all the factors (age, sex, marital status, occupation, social class, literacy, smoking, alcohol intake, type of psychiatric morbidity, and personality trait) that could predict the default, only smoking (OR: 3.76, 95\% CI: 1.71-8.28, $P=0.001$ ); alcoholism (OR: 15.42 95\% CI: 6.67-35.72, $P<0.001$ ), and neurotic personality trait (OR: 3.54, 95\% CI: 1.61-7.79, $P=0.002$ ) were related to the default. Similar observations were made by others that tobacco smoking and alcoholism were significantly associated with default in TB patients. ${ }^{[32-34]}$ The habit of smoking and consuming alcohol is the reflection of the subject's personality. There was no significant difference in default rate among different types of psychiatric morbidity.

The present study had few limitations. First, the assessment tool for psychiatric illness and personality traits used in this study was an objective tool, requires some expertise, and cannot be easily applied at peripheral health centers. Second, the retreatment category II cases were not included in the study. These patients default more as compared to other categories and hence effectiveness of psychiatric assessment and intervention in such patients must be evaluated in further studies. Finally, comparison of treatment outcome between patients with psychiatric morbidity and those who had not was not done.

\section{CONCLUSION}

Majority of 'TB patients have psychiatric morbidity. Psychiatric assessment before starting DOTS therapy might reduce treatment interruption and increase the treatment success. Similarly, personality assessment at baseline will identify the patients who are more likely to default from treatment and behavioral therapy; while counseling in advance will prevent them from default. This can be easily done by DOTS provider. Reducing default rate will eventually decrease the treatment failure, drug resistance, and resources spent on default retrieval.

\section{ACKNOWLEDGEMENT}

Late Prof. Shiv Sharma Agnihotri, Department of Psychiatry, Ganesh Shankar Vidyarthi Memorial Medical College, Kanpur, India.

\section{REFERENCES}

1. Rajeswari R, Balasubramanian R, Muniyandi M, Geetharamani S, Thresa X, Venkatesan P. Socio-economic impact of tuberculosis on patients and family in India. Int J Tuberc Lung Dis 1999;3:869-77.

2. Vijay S, Balasangameswara VH, Jagannatha PS, Saroja VN Kumar P. Defaults among Tuberculosis Patients treated under DOTS in Bangalore city. Indian J Tub 2003;50:185.

3. Ramachandran V, Thiruvengadam KV, Zakaria MG, Kathiresar A. Psychiatric symptoms and personality trials in pulmonary tuberculosis patients. Indian J Psychiatry 1974;16:170-4.

4. Natani GD, Jain NK, Sharma TN, Gehlot PS, Agarwal SP, Koolwal S, et al. Depression in tuberculosis patient correlation with duration of disease and response to anti tuberculosis chemotherapy. Indian J Tuber 1985;32:195-8.

5. Janmeja AK, Das SK, Bhargava R, Chavan BS. Psychotherapy improves compliance with tuberculosis treatment. Respiration 2005;72:375-80.

6. Husain MO, Dearman SP, Chaudhry IB, Rizvi N, Waheed W. The relationship between anxiety, depression and illness perception in tuberculosis patients in Pakistan. Clin Pract Epidemiol Ment Health 2008;4:4.

7. Moussas G, Tselebis A, Karkanias A, Stamouli D, llias I, Bratis D, et al. A comparative study of anxiety and depression in patients with bronchial asthma, chronic obstructive pulmonary disease and tuberculosis in a general hospital of chest diseases. Ann Gen Psychiatry 2008;7:7.

8. Training module for medical practitioner For DOTS Treatment, see website. Available from: http://www.tbcindia.nic.in 24 Oct 2012.

9. Abramson JH. The cornell medical index as an epidemiological tool. Am J Public Health Nations Health 1996;56:287-98.

10. Jalota S, Kapoor SD. Manual of the Hindi Version of Cattell's Sixteen Personality Factor Questionnaire. Varanasi: Psycho Centre, (1964).

11. $16 \mathrm{PF}$ is a trademark of the Institute for Personality and Ability Testing, see. Available from: http://www.IPAT.com [Last accessed date 18 may 2013].

12. Cattell RB, Cattell AK, Cattell HE. 16PF, $5^{\text {th }}$ ed. Questionnaire. Champaign: Institute for Personality and Ability Testing; 1993.

13. Prochaska JO, DiClemente CC. Stages and processes of self-change of smoking: Toward an integrative model of change. J Consult Clin Psychol 1983;51:390-5.

14. Brooks CM, Richards JM, Kohler CL, Soong SJ, Martin B, Windsor RA, et.al. Assessing adherence to asthma medication and inhaler regimens: A psychometric analysis of adult self-report scales. Med Care 1994;32:298-307.

15. Allen EA, Stewart M, Jenny P. The efficiency of post-sanatorium management in tuberculosis. A study of one thousand tuberculous patients discharged from sanatoria in Ontario. Can J Public Health 1964;55:323-33.

16. Zaki MH, Edelstein S, Josephson RA, Weisberg SR. Regularity of drug administration among hospitalized and ambulatory tuberculous patients. Am Rev Resp Dis 1968;97:136-9.

17. Kelloway JS, Wyatt RA, Adlis SA. Comparison of patients' compliance with prescribed oral and inhaled asthma medications. Arch Intern Med 1994;154:1349-52.

18. Zwarenstein M, Schoeman JH, Vundule C, Lombard CJ, Talley M. Randomised controlled trial of self supervised and directly observed treatment of tuberculosis. Lancet 1998;352:1340-3.

19. Moudgil AC, Pershad D. Psycho-social survey of tuberculosis patients of a sanatorium. Indian J Tuberc 1972;19:34-8.

20. Purohit DR, Purohit SD, Dhariwal ML. Incidence of depression in hospitalized TB patients. Indian J Tuberc 1978;25:147-1.

21. Tandon AK, Jain SK, Tandon RK, Asare R. Psychosocial study of tuberculosis patients. Indian J Tub 1980;17.

22. Eram U, Khan IA, Tamanna MZ, Khan Z, Khaliq N, Abidi AJ. Patient perception of illness and initial reaction to the diagnosis of tuberculosis. Indian J Com Med 2006;31.

23. Seetha MA, Srikantaramu N, Aneja KS, Singh H. Influence of motivation of patients and their family members on the drug collection by patients. Indian J Tuberc 1981;28:182-90.

24. Uplekar M, Rangan S. Alternative approaches to improvement in treatment adherence in tuberculosis control programme. Indian J Tuberc 1995;42:67-74.

25. Hasker E, Khodjikhanov M, Usarova S, Asamidinov U, Yuldashova U, van der Werf MJ, et al. Default from tuberculosis treatment in Tashkent, 
Uzbekistan; who are these defaulters and why do they default? BMC Infect Dis 2008;8:97.

26. Sumartojo E. When tuberculosis treatment fails. A social behavioral account of patient adherence. Am Rev Respir Dis 1993;147:1311-20.

27. Walker JL. Some personality characteristics noted among tuberculosis patients, with implications for a counselor. Ment Hyg 1949;33:453-6.

28. Muldoon JF. Some psychological concomitants of tuberculosis and hospitalization: A preliminary study. Psychosom Med 1957;19:307-14.

29. Vernier C, Barrell R, Cummings J, Dickerson J, Hooper H. Psychosocial study of the patients with pulmonary tuberculosis a cooperative research approach. Psychological Monographs 1961;75:1-32.

30. Charles $\mathrm{N}$. Influence of initial and repeated motivation on case-holding in North Arcot district. Indian J Tuberc 1991;38:69-71.

31. Suhadev M, Ganapathy S, Sivasubramanium S, Devi TS. A retrospective study of 'non-compliant' patients in controlled clinical trials of short course chemotherapy. Indian J Tuberc 1995;42:221-4.

32. Manoharam E, John KR, Joseph A, Jacob KS. Psychiatric morbidity, patients' perspectives of illness and factors associated with poor medication compliance among the tuberculosis in Vellore, South India. Indian J Tub 2000;48:77-80.

33. Vijay S, Kumar P, Chauhan LS, Vellopore BH, Kizhakkethil UP, Rao SG. Risk factors associated with default among new smear positive TB patients treated under DOTS in India. PLos One 2010;5:e10043.

34. Dujaili JA, Sulaiman SY, Awaisu A, Muttaif AR, Blebil AQ. Outcomes of tuberculosis treatment: A retrospective cohort analysis in Penang, Malaysia. J Public Health 2010;19:183-9.

How to cite this article: Chaudhri S, Bansal A, Singh A, Sampath A, Verma AK, Tripathi A, Mishra M, Verma SK. Impact of psychiatric profile and personality trait on directly observed tuberculosis treatment outcome. Int J Med Public Health 2013;3:303-8.

Source of Support: Nil, Conflict of Interest: None declared. 